\title{
Accelerating the Move Towards Online Learning Through Cloud Platforms in Higher Education Sectors Using Smart Devices during COVID-19
}

\author{
https://doi.org/10.3991/ijim.v15i10.22163 \\ Arul Leena Rose. P. J, Ananthi Claral Mary. T ${ }^{(\varpi)}$ \\ SRM Institute of Science and Technology, Chengalpattu, India \\ ananthiclaral@gmail.com
}

\begin{abstract}
Education is essential for the progress of humankind. The function of education is to teach one to think intensively and critically. Education policies are entering into a new pathway. Due to climatic and geographical conditions in many areas of the world, it is challenging to establish classes. Many students feel difficulties in leaving their motherland for further education due to the limited economy. Learning using technological components like smart devices is continually growing. Several education institutions provide services through the web using cloud-based technology to ease the students and cultivate their education. The employment of smart devices has a great perspective on teaching and learning. During COVID-19, the cloud platform helps students and faculties learn and even stay in their residential areas. This paper aims to outline: attitude and opinion of smart devices used by higher education students and their self-efficacy in participating in online classes. This teaching strategy makes a significant contribution to digital pedagogy. It includes approximately 360 respondents. The results revealed that students' perceptions of device usage, connectivity, and time duration had a statistically significant effect on cloudbased online learning, and self-efficacy depicts a positive impact on their online classes. Thus, smart devices play a vital role in extending learning out of the classroom anywhere, anytime.
\end{abstract}

Keywords - COVID-19, smart devices, wireless technologies, cloud computing

\section{Introduction}

Traditionally the educational environment begins with classroom learning, where students are required to attend classes. Due to the corona virus problem, schools and universities worldwide are closed from the mid of March 2020. It was estimated that education sectors had faced many problems due to the widespread virus. The quality of education is minimized; hence, students cannot run off with the current technologies. Lack of faculty members and inadequate infrastructure facilities lead to the increasing percentage of students moving out of the higher education sectors. All these problems can be solved by using the cloud in education. The recent Learning Management System (LMS) of online learning can be accessed using smart devices such 
as smartphones, laptops, tablets, desktop PCs. These devices' applications are integrated with wireless technologies, namely broadband, WIFI, 4G, and 5G telecommunication networks, allowing students to access learning resources like lecture materials, assignments, quizzes, and collaborate meetings without any restrictions to time and location. Due to the COVID-19 pandemic, the on-campus teaching is transferred to emergency remote teaching. In delivering teaching services to students, cloud technology is facilitating an educational revolution to a great extent. Anna Qian Sun, Xiufang Chen [2] reviewed 47 articles, produced evidence-based effective practices in online teaching, learning and stated about the evolution of online education. They also discussed about the online learning community which helps in making a collaborative learning environment. Vusala Teymurova et al. [21] studied the implementation level of learning methods using mobile technologies in higher education. Results show that integration of tradition and innovation depends on the usage of cloud services and mobile applications.

The present study investigates the effect of cloud-based online learning and the extent to which the graduate students' gender and time duration of devices connected online influence smart devices. We have also observed the self-efficacy of the students participating in online classes. This paper is organized in the following manner: 1) introduction 2) an extensive literature review 3) objectives 4) methodology 5) data analysis 6) results 7) limitations of the study and recommendations 8) discussions and conclusion.

\subsection{Radical shift to new methodologies in education}

Cloud-based online learning helps educators complete the entire syllabus, thus satisfying the students' learning needs. The educators can teach the students using cloud platforms: YouTube, Zoom, Google Classroom, Microsoft Teams, WebEx, GoToMeeting, Skype, etc., as the same procedure is followed. In higher education institutions, examinations were conducted online by using these platforms. This study revealed that the majority of the students use smartphones to access online classes. The unprecedented growth of smart mobile phones ensures a shift in the educational landscape. As mobile technology reaches the far corners of the world, it allows more students to access the internet for online learning. The reliance on mobile devices is more than just a convenience factor. For low economic students, smartphones may be the only accessible path to online learning that enhances students' self-directed learning.

\subsection{Cloud empowers online learning}

Cloud Computing is one of today's most enticing technology areas due to its scalability, accessibility, flexibility, and cost-efficiency. Mobile phone users will get numerous benefits with cloud computing technologies. The online learning application can be easily created without capital investment in infrastructure and services. The virtual live classroom helps to improve the motivation among the students. The advantages of cloud-based online learning: 
1. Access to Remote location: The learning materials can be accessed by the students remotely. This enhances the participation of distance learners entirely in the course.

2. Crash Protection: Students and educators cannot access their course materials if our institution's eLearning system crashes. We can use cloud-based systems, as it has no risk.

3. Real-time data backup: The course material will not be lost, even if an individual educator's PC breaks down as the cloud securely backs up data in real-time.

4. Support for an extensive range of education styles: The cloud-based online learning platform can be turned into an attractive multi-mode education site, as it supports video conferencing, interactive quizzes, student conversation forums, whiteboards, etc.

5. Adaptation to our requirements: Educators can develop and build their digital learning environments to suit their needs.

\subsection{Integrating smart devices with learning and instruction}

Mobile technologies have enormous prospects for expediting more revolutionary methods in education. Smartphones, laptops, tablets, desktop PCs are the smart devices used by students. Smartphones are powerful communication devices. In recent years, most of the global population use smartphones due to their wide range of applications. It runs complete operating system software like Google Android, which provides a standard interface. It provides features like access to the internet, e-mail, instant messaging, e-book reader, etc. Laptops became very famous due to their size, portability, and capabilities. Tablet has a touchscreen to operate with a stylus or digital pen instead of using a keyboard or mouse. Unlike traditional desktop computers, laptops and tablets offer advanced computing capabilities and can support problembased models, allowing learning groups to satisfy their requirements. There is an increasing interest in exploring online learning due to the improvement of network communications and desktop machines' processing power. The current trend of college student's culture is using wireless technologies and mobile devices. These educational process innovations ensure subject content learning and ease communication, analytical and creative thinking.

\section{$2 \quad$ Literature Review}

Globally the entire education system is connected to the virtual environment. Due to the COVID-19 situation, the education sector has a drastic shift towards online learning. The literature review articles were selected based on online learning using a cloud platform, mobile education, and our proposed research questions. Dragan Cvetkovic et al. experimented with 500 respondents, and results showed that online learning established in a cloud environment is more accessible and displays improved effectiveness compared to presently using the classical server-oriented system. They concluded that most teachers agree that private cloud infrastructure improves the effi- 
ciency of preparing intended courses for e-education experience, but they have to set up the virtual machines [5]. Michail Kalogiannakis and Stamatios Papadakis conducted a study of early childhood education in Greece. It aims to examine the pre-service kindergarten teacher's approval of ScratchJr as an interactive and educational tool for science teaching and computational thinking. The results illustrate a significant increase in the use of ScratchJr among pre-service kindergarten teachers' self-efficacy and are interested in using it in their everyday practice for science education in the future [12]. Delna Sebastian, Saravanan KN predicted the students' academic performance based on their skills, behavior, and ability using the KNN classification algorithm. They illustrated that KNN had attained $97.61 \%$ accuracy on the test data set, and they found that it is the best solution for prediction [4]. Their study's fundamental aim is to thoroughly understand whether virtual reality helps provide concept precision and makes the s education easy temper. They concluded that there are remarkable improvements of students' practical exams thoroughly they find it easy to recollect the concepts. Their fear towards maths and science subjects has gone down. Stamatios Papadakis attempted to examine the extent to which teachers' age and gender manipulate mobile devices in class. The results revealed that there is no gender and age difference [17].

Rohit Maheshwari et al. [15] represented an architecture based on a cloud environment that can be used to improve education procedures to meet students' present requirements and discuss some challenges that educational institutes should follow to adopt cloud computing into teaching-learning environment. Stamatios Papadakis et al. [19] observed that mobile phones were not ideal for accessing Moodle. Students referred to screen size as a usability issue. Mobile device monitors with large screens can render higher resolutions at more readable sizes. They expressed the necessity of mobile access that is user-friendly. The findings pointed out the necessity of using modern digital equipment, namely smart mobile phones and tablets. Jyoti Prakash Mishra et al. discussed various educational sectors like distance education, higher education, open education, vocational health education, and mobile education, which follow the various cloud computing approaches [8].

Karen Sutherland et al. conducted a pilot study that discovers the procedures, approaches, and observations of academics regarding social media usage in teaching. The best substantial outcomes in their study are broadcasting information to the students, and social media is primarily being used by academics [9]. Krishna et al. constructed a student model by extracting data from Moodle to forecast their academic performance. The authors have used the Classification and Regression Trees (CART) decision tree algorithm to classify students and predict those at risk [10]. Christopher et al. analyzed the various levels of cloud services and deployment models. They have suggested a technology adoption model for cloud computing services. They concluded that they could choose any particular cloud computing model [3]. Alex Wilson and Chris Wilson, Gabi Witthaus [1] argued that to share teaching experiences and innovations teaching forum has clear benefits and positive perceptions. They concluded that teaching forums' participation and impact vary with faculty seniority and demographic characteristics on teaching practice in higher education. Sonny and Zachary [16] compared traditional face-to-face learning outcomes lectures with various for- 
mats of video lectures. Eden C. Callo and Alberto D. Yazon examined the features inducing eagerness in online teaching and learning. The results revealed that respondent device access, connectivity, familiarity, ability, preparation, self-efficacy, and technology experience meaningfully inspired their willingness on the behavior of online learning and teaching [6].

Stamatios Papadakis et al. investigated the magnitude of utilizing and working educational applications for kids. Exploratory Factor Analysis was applied to explore and establish the proposed questionnaire. The findings suggested that usability is a primary factor in facilitating kids' involvement in learning and enjoying [18]. Moh. Muzammil et al. analyzed the results of student engagement and satisfaction towards online learning influenced by student interaction [13]. Florence Martin et al. examined current digital technologies used by faculties based on their competence, motivation, and perception of importance. In [7], their findings depicted that the faculty members' use of a learning management system has the maximum importance and capability. Patrick Otto et al. conducted a quantitative research method to handle risks related to mobile device usage. The results specified that mobile devices were utilized in their organizations by most respondents [14]. WenYa Lai et al. [22] conducted a study to examine the stress caused by teaching; learning leads to anxiety among teachers that affects their efficiency and performance. The results illustrated that teaching experience has a positive effect, while there is a negative effect on perception towards self-efficacy on work and life experiences. They suggested the management to take a series of measures to decrease teachers' anxiety, thus improving their self-efficacy. Maria Drolia et al. aims to outline challenges in refugees' education, their living conditions, education requirements, usage of smart mobile devices, and their contradictory perceptions about mobile learning. They concluded that refugees could access education through mobile, thereby increasing refugee education quality [11]. Stamatios Papadakis [20] presented robotics kits and robots to build computational thinking skills, knowledge and bridges the theory-practice gap that can be used at early childhood and first primary classes. The purpose of the article was to notify educational community to take decisions when this technology is introduced in class room.

Based on literature review, there is a necessity for modern digital equipment for teaching-learning environment. The literature review results specified that mobile devices were utilized in organizations and institutions by the majority of respondents. However, it has not mentioned about implementation of online learning at the university level. We proceeded with choosing Google Classroom as the cloud platform and Google Meet for video conferencing. We studied the impact of graduate student's perceptions in accessing online classes through smart devices.

\section{Objectives}

In the circumstance of this background, the current study's key objective is to investigate the usage of smart devices to access online classes during COVID-19 by college students around Tamil Nadu, the state of India. The main objective is to study 
gender-related differences in the habits of smart device users. The following research questions are focused in this study:

1. To assess if there is a significant effect of gender on perception of using device type control for the duration.

2. To investigate is there a significant effect of gender on perception of using device connectivity controlling for the time duration.

3. To what extent the respondent's self-efficacy explain their readiness to learn online?

\section{$4 \quad$ Methodology}

The research is conducted by using the procedure of the survey method. Primary data have been collected from smart device users, students with different demographic characteristics from numerous colleges and universities around Tamil Nadu through a structured questionnaire designed using Google Forms. Convenience sampling was used for data collection. An online link was given to the total population of 360 respondents to access Google Forms.

\section{Data Analysis}

Data collection was carried out using a questionnaire adapted from Eden and $\mathrm{Al}$ berto [6], which the authors adjusted to suit this study. The targeted respondents were offered a questionnaire that included quantitative and qualitative questions about their experience of using smart devices to access cloud-based online classes. It included three parts. Part 1 interrogated about the necessary demographic information. Part 2 questioned the type of smart device, ownership, type of connectivity, duration of device connected online. Part 3 enquired about the self-efficacy of the students participating in online classes.

\subsection{Questionnaire responses}

The respondents' demographic details are depicted in Table 1, of which $71 \%$ were males, and $29 \%$ were females between the age group of 17 and 45 years. The students were from various specializations, like B.E, B.Sc. Computer Science, B.C.A, B.Com, and MCA. Most of the respondents, 38\%, were from the age group 20, followed by $21-45$ (34\%), while only $28 \%$ belong to $17-19$. The majority of the students belong to city background (60\%) compared to those in village background (40\%). Most of the students were day scholars (82\%). Table 2 represents the student's share of smart devices, device connectivity, and time duration. It depicts that $67 \%$ of the students use a smartphone, $28 \%$ of the students use a laptop, and $1 \%$ of students use a tablet, and $4 \%$ of the students use desktop PC for accessing the online classes. 5\% of students use broadband, $22 \%$ use WIFI, $72 \%$ use mobile data, and $1 \%$ use other device connectivity modes. Further, the statistical results show that $24 \%$ of students utilize the devices 
for about 1-2 hours, $37 \%$ of students use about 3-4 hours, $34 \%$ have unlimited access, and $5 \%$ cannot use the devices.

Table 1. Demographic characteristics of the study participants

\begin{tabular}{|l|l|c|c|}
\hline \multicolumn{1}{|c|}{ Variable } & \multicolumn{1}{|c|}{ Label } & Frequency $(\mathbf{n = 3 6 0})$ & Percentage \\
\hline \multirow{3}{*}{ Gender } & Male & 257 & 71.39 \\
\cline { 2 - 4 } & Female & 103 & 28.61 \\
\hline \multirow{3}{*}{ Age Range } & $17-19$ years old & 101 & 28.06 \\
\cline { 2 - 4 } & 20 years old & 137 & 38.06 \\
\cline { 2 - 4 } & $21-45$ years old & 122 & 33.89 \\
\hline \multirow{2}{*}{ Background } & Village & 145 & 40.28 \\
\cline { 2 - 4 } & City & 215 & 59.72 \\
\hline \multirow{2}{*}{ Accommodation } & Hostelate & 64 & 17.78 \\
\cline { 2 - 4 } & Day scholar & 296 & 82.22 \\
\hline
\end{tabular}

Table 2. Student share of smart devices, device connectivity, time duration

\begin{tabular}{|c|l|c|c|}
\hline \multicolumn{1}{|c|}{ Variable } & \multicolumn{1}{|c|}{ Label } & Frequency & Percentage \\
\hline \multirow{5}{*}{ Smart Devices } & Smartphone & 240 & 66.67 \\
\cline { 2 - 4 } & Laptop & 99 & 27.50 \\
\cline { 2 - 4 } & Tablet & 5 & 1.39 \\
\cline { 2 - 4 } & Desktop PC & 16 & 4.44 \\
\cline { 2 - 4 } & Total & 360 & 100.00 \\
\hline \multirow{5}{*}{ Device Connectivity } & Broadband & 18 & 5.00 \\
\cline { 2 - 4 } & WIFI & 79 & 21.94 \\
\cline { 2 - 4 } & Mobile Data & 260 & 72.22 \\
\cline { 2 - 4 } & Others & 3 & 0.83 \\
\cline { 2 - 4 } & Total & 360 & 100.00 \\
\hline \multirow{5}{*}{ Time Duration } & About 1-2 hours & 85 & 23.61 \\
\cline { 2 - 4 } & About 3-4 hours & 134 & 37.22 \\
\cline { 2 - 4 } & Unlimited Access & 122 & 33.89 \\
\cline { 2 - 4 } & Cannot Use the Devices & 19 & 5.28 \\
\cline { 2 - 4 } & Total & 360 & 100.00 \\
\hline
\end{tabular}

\subsection{Device ownership}

Table 3 depicts the share of device ownership. It describes the devices that 360 students have to access online classes. It may be personally owned, shared with friends, family members, or may not have any device. This depicts that most of the students use smartphones, which they own, to access online classes. 
Table 3. Students share of device ownership

\begin{tabular}{|l|c|c|c|c|c|}
\hline \multicolumn{1}{|c|}{ Ownership } & $\begin{array}{c}\text { Personally } \\
\text { Owned }\end{array}$ & $\begin{array}{c}\text { Shared with } \\
\text { Friends }\end{array}$ & $\begin{array}{c}\text { Shared with } \\
\text { Family Members }\end{array}$ & $\begin{array}{c}\text { Not Acquired/ } \\
\text { No Access }\end{array}$ & Total \\
\hline Smartphone & 192 & 13 & 33 & 2 & 240 \\
\hline Laptop & 82 & 4 & 13 & 0 & 99 \\
\hline Tablet & 4 & 0 & 1 & 0 & 5 \\
\hline Desktop PC & 12 & 0 & 4 & 0 & 16 \\
\hline Total & 290 & 17 & 51 & 2 & 360 \\
\hline
\end{tabular}

\subsection{Type of device connectivity}

The significant feature of smart devices is connectivity that is necessary to create an effective online learning environment. The capability of wireless communication enables them to connect to the internet, makes these devices "smart." The current generation of online learning is shaped by computer technologies' growing service, namely the internet, WWW in higher education. Due to the drastic increase in availability, high-speed internet connection, broadband technology significantly impacts the time to search for information on the internet. With reliable access to the internet, students and teachers engage globally to leverage high-quality learning resources. Table 4 depicts that most of the students use mobile data from their smartphone to access online classes.

Table 4. Students share device connectivity

\begin{tabular}{|l|c|c|c|c|c|}
\hline \multicolumn{1}{r|}{ Connectivity } & Broadband & WIFI & Mobile Data & Others & Total \\
\hline Smartphone Type & 1 & 29 & 207 & 3 & 240 \\
\hline Laptop & 11 & 42 & 46 & 0 & 99 \\
\hline Tablet & 1 & 2 & 2 & 0 & 5 \\
\hline Desktop PC & 5 & 6 & 5 & 0 & 16 \\
\hline Total & 18 & 79 & 260 & 3 & 360 \\
\hline
\end{tabular}

\subsection{Time duration of device connection}

The time required for the device to be connected online is 1-2 hours to 3-4 hours. Some students may have unlimited access, and some cannot use the devices owing to network problems. Table 5 shows the share of device duration. It depicts that most students use a smartphone with time duration of 3-4 hours connectivity. 
Table 5. Students share of time duration

\begin{tabular}{|l|c|c|c|c|c|}
\hline \multicolumn{1}{|c|}{ Time Duration } & $\begin{array}{c}\text { About 1-2 } \\
\text { hours }\end{array}$ & $\begin{array}{c}\text { About 3-4 } \\
\text { hours }\end{array}$ & $\begin{array}{c}\text { Unlimited } \\
\text { Access }\end{array}$ & $\begin{array}{c}\text { Cannot Use } \\
\text { the Devices }\end{array}$ & Total \\
\hline Smartphone & 71 & 90 & 65 & 14 & 240 \\
\hline Laptop & 11 & 38 & 45 & 5 & 99 \\
\hline Tablet & 0 & 1 & 4 & 0 & 5 \\
\hline Desktop PC & 3 & 5 & 8 & 0 & 16 \\
\hline Total & 85 & 134 & 122 & 19 & 360 \\
\hline
\end{tabular}

\section{$6 \quad$ Results}

\subsection{Research question - 1}

- H0: There is no relationship between gender and device type, controlling for the time duration.

- H1: There is a relationship between gender and device type, controlling for the time duration.

Analysis of covariance (ANCOVA) is conducted in R to test whether the difference between the groups is statistically significant. The critical variable of the study is the application of smart devices. The experimental group had an intervention that used smartphones, laptops, tablets, and desktop PCs for online learning. The device type is used as a significant dependent variable compared against gender and time duration of the device connected online. A regression model is created having "time duration" as the predictor variable, "gender" as a categorical variable, and "device type" as an outcome variable, taking into consideration the interaction between "gender" and "time duration."

Table 6. Model with interaction between time duration and gender

\begin{tabular}{|l|c|c|c|c|c|}
\hline \multicolumn{1}{|c|}{ Sources } & Df & Sum Sq & Mean Sq & F value & $\operatorname{Pr}(>\mathbf{F})$ \\
\hline TimeDuration & 1 & 8.25 & 8.247 & 16.027 & $7.6 \mathrm{e}-05 * * *$ \\
\hline Gender & 1 & 1.17 & 1.169 & 2.271 & 0.1327 \\
\hline TimeDuration: Gender & 1 & 1.94 & 1.937 & 3.765 & 0.0531. \\
\hline Residuals & 356 & 183.18 & 0.515 & & \\
\hline
\end{tabular}

The result of ANCOVA in Table 6 reveals that time duration has a significant effect on device type as the F-value is 16.027 and the p-value is less than 0.05 . Gender has no significant effect on device type as the F-value is 2.271 , and the p-value is more significant than 0.05 . The interaction between these two variables is not significant as the F-value is 3.765 and the p-value is more than 0.05 . 
Table 7. Model without interaction between time duration and gender

\begin{tabular}{|l|c|c|c|c|c|}
\hline \multicolumn{1}{|c|}{ Sources } & Df & Sum Sq & Mean Sq & F value & Pr(>F) \\
\hline TimeDuration & 1 & 8.25 & 8.247 & 15.904 & $8.09 \mathrm{e}-05$ *** \\
\hline Gender & 1 & 1.17 & 1.169 & 2.254 & 0.134 \\
\hline Residuals & 357 & 185.12 & 0.519 & & \\
\hline
\end{tabular}

Table 7 depicts, ANCOVA result that time duration has a significant effect on device type as the F-value is 15.904 and the p-value is less than 0.05 . Gender has no significant effect on device type as F-value is 2.254 , and the p-value is more significant than 0.05 . Table 8 shows the comparison between the two models. For this, we use ANOVA().

Table 8. Comparing two models

\begin{tabular}{|c|c|c|c|c|c|c|}
\hline Sources & Res. Df & RSS & Df & Sum of Sq & F & $\operatorname{Pr}(>\mathbf{F})$ \\
\hline 1 & 356 & 183.18 & & & & \\
\hline 2 & 357 & 185.12 & -1 & -1.9373 & 3.7651 & 0.05312. \\
\hline
\end{tabular}

As the F-value is 3.7651 and the p-value is greater than 0.05 , there is no significant effect of gender on the perception of using device type controlling for the duration. Figure 1 illustrates the time duration of the usage of smart devices by gender.

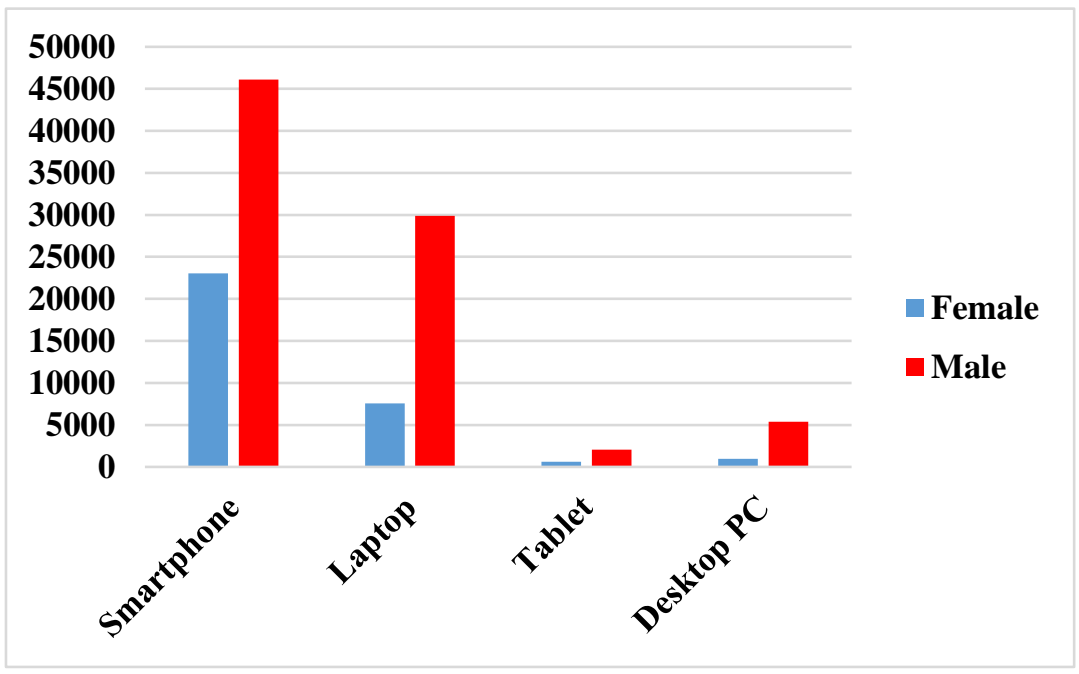

Fig. 1. Time duration on smart devices by category

\subsection{Research question -2}

- H0: There is no relationship between gender and device connectivity, controlling for the time duration. 
- H1: There is a relationship between gender and device connectivity, controlling for the time duration.

ANCOVA is conducted in $\mathrm{R}$ to test the difference between the groups are statistically significant. The critical variable of the study is the application of device connectivity. The experimental group had an intervention that used broadband, WIFI, mobile data, and others for online learning. Device connectivity is a significant dependent variable compared to gender and time duration of devices connected online. A regression model is created having "time duration" as a covariate, "gender" as a grouping variable, and "device connectivity" as the outcome variable, taking into consideration interaction between "gender" and "time duration."

Table 9. Model with interaction between time duration and gender

\begin{tabular}{|l|c|c|c|c|c|}
\hline \multicolumn{1}{|c|}{ Sources } & Df & Sum Sq & Mean Sq & F value & Pr(>F) \\
\hline TimeDuration & 1 & 11.95 & 11.952 & 40.156 & $7.09 \mathrm{e}-10 * * *$ \\
\hline Gender & 1 & 0.02 & 0.022 & 0.072 & 0.7880 \\
\hline TimeDuration: Gender & 1 & 1.22 & 1.221 & 4.102 & $0.0436 *$ \\
\hline Residuals & 356 & 105.96 & 0.298 & & \\
\hline
\end{tabular}

As Table 9 shows, the result of ANCOVA revealed that time duration significantly affects device connectivity as the F-value is 40.156 and the p-value is less than 0.05 . Gender has no significant effect on device connectivity as F-value 0.072 , and the pvalue is more significant than 0.05 . Nevertheless, the interaction between these two variables is significant as F-value is 4.102 and the p-value is less than 0.05 .

Table 10. Model without interaction between time duration and gender

\begin{tabular}{|l|c|c|c|c|c|}
\hline \multicolumn{1}{|c|}{ Sources } & Df & Sum Sq & Mean Sq & F value & Pr(>F) \\
\hline TimeDuration & 1 & 11.95 & 11.952 & 39.810 & $8.29 \mathrm{e}-10 * * *$ \\
\hline Gender & 1 & 0.02 & 0.022 & 0.072 & 0.789 \\
\hline Residuals & 357 & 107.18 & 0.300 & & \\
\hline
\end{tabular}

The result of ANCOVA in Table 10 shows that time duration significantly affects device connectivity as the F-value is 39.810 and the p-value is less than 0.05 . Gender has no significant effect on device connectivity as F-value is 0.072 , and the p-value is more significant than 0.05 . Table 11 shows the comparison between the two models. For this, we use the ANOVA function.

Table 11.

Comparing two models

\begin{tabular}{|c|c|c|c|c|c|c|}
\hline Sources & Res. Df & RSS & Df & Sum of Sq & F & $\operatorname{Pr}(>\mathbf{F})$ \\
\hline 1 & 356 & 105.96 & & & & \\
\hline 2 & 357 & 107.18 & -1 & -1.2209 & 4.1019 & $0.04358^{*}$ \\
\hline
\end{tabular}

As the F-value is 4.1019 and the p-value is less than 0.05 , there is a significant effect of gender on perception of device connectivity controlling for the duration. Figure 2 depicts the time duration of the usage of device connectivity by gender. 




Fig. 2. Time duration on device connectivity by category

\subsection{Research question - 3}

Self-efficacy of students participating in online learning: Canadian-American psychologist Albert Bandura is responsible for several contributions to psychology and education, including social cognitive therapy. According to him, self-efficacy means the individual's belief in their capacity to execute behaviors essential to yield performance attainments. Table 12 shows the questionnaire statements' results regarding the self-efficacy of respondent's assessment of their capacity to participate in online learning. There are ten statements, and the mean score for each statement was used to describe each one's strength. The respondents rated themselves using the Likert scale of 1 to 5. With one being correlated to Agree (A), 2 Disagree (DA), 3 Undecided (UD), 4 Strongly Disagree (SD), and 5 Strongly Agree (SA). The highest mean score is "Students can remain calm when facing difficulties in online learning" $(M=7.83)$. The second highest mean score is "If they invest essential effort in online learning, they could solve the majority of problems $(\mathrm{M}=7.80)$ followed by "Handling unforeseen situations in online learning" ( $M=7.31)$. The lowest mean score is "If I am in trouble while accessing the online course, I can usually think of a solution" $(\mathrm{M}=3.21)$. The second-lowest mean score is "I can usually handle whatever comes my way in online learning" $(\mathrm{M}=1.53)$. 
Table 12. Student's self-efficacy in participating online classes

\begin{tabular}{|l|c|c|c|c|c|c|c|}
\hline \multicolumn{1}{|c|}{ Statements } & A & DA & UD & SD & SA & Mean & SD \\
\hline $\begin{array}{l}\text { If you strive hard enough in online learning, can you solve } \\
\text { challenging problems? }\end{array}$ & 180 & 59 & 66 & 31 & 24 & 6.46 & 62.96 \\
\hline $\begin{array}{l}\text { Can you find ways and means to acquire what you desire in } \\
\text { online learning if someone opposes you? }\end{array}$ & 191 & 55 & 79 & 16 & 19 & 6.34 & 71.49 \\
\hline $\begin{array}{l}\text { Is it simple for you to stick to your aims and achieve your } \\
\text { goals through online learning? }\end{array}$ & 126 & 106 & 56 & 56 & 16 & 6.43 & 43.93 \\
\hline $\begin{array}{l}\text { Are you secure that you could deal resourcefully with unpre- } \\
\text { dicted events in online learning? }\end{array}$ & 142 & 97 & 78 & 31 & 12 & 6.93 & 52.06 \\
\hline $\begin{array}{l}\text { Do you know how to tackle unexpected situations in online } \\
\text { learning? }\end{array}$ & 153 & 77 & 100 & 20 & 10 & 7.31 & 58.99 \\
\hline $\begin{array}{l}\text { Can you remain calm when facing difficulties in online learn- } \\
\text { ing? }\end{array}$ & 180 & 77 & 45 & 42 & 16 & 7.83 & 64.14 \\
\hline $\begin{array}{l}\text { If you invest essential effort in online learning, could you } \\
\text { solve the majority of problems? }\end{array}$ & 178 & 83 & 56 & 28 & 15 & 7.80 & 64.80 \\
\hline $\begin{array}{l}\text { Can you find numerous solutions in online learning when you } \\
\text { are opposed to a problem? }\end{array}$ & 184 & 74 & 67 & 22 & 13 & 5.25 & 68.11 \\
\hline $\begin{array}{l}\text { If you are in trouble while accessing the online course, can } \\
\text { you usually think of a solution? }\end{array}$ & 202 & 60 & 65 & 15 & 18 & 3.21 & 76.25 \\
\hline $\begin{array}{l}\text { Could you usually handle whatever comes your way in online } \\
\text { learning? }\end{array}$ & 183 & 54 & 82 & 0 & 14 & 1.53 & 72.71 \\
\hline
\end{tabular}

\section{$7 \quad$ Limitations and Recommendations}

This study has some limitations, in addition to the empirical findings. Due to the sampling technique used for this study and the small sample size, the result cannot be generalized. The findings can be extended to large samples and varied populations, e.g., faculty, administrators.

In the context of delivering high-quality remote education, the following recommendations may be considered:

1. Laptop/smartphone/tablet provides technical support to the needy students to have easy access to an internet connection.

2. The use of flexible online learning using smart devices must be discussed thoroughly.

3. The University must hasten the computerization system to facilitate the quality of online service delivery and create a cloud campus.

4. To advance the level of education, the institutions should have an agreement with trusted cloud service providers.

5. Several workshops have to be conducted on cloud and cloud services.

6. Students and faculties should have hands-on training to execute online teaching, learning, and creating a virtual classroom. 


\section{Discussion and Conclusion}

This study examined to outline the usage of smart devices by the students of higher education sector for online learning. The cloud-based online learning platforms are flexible, dynamic, and accessed even in a limited bandwidth. These innovative technologies play a vital role in encouraging more operative social interaction and the learning community's development. It encourages higher education in remote areas while reducing the work burden of teachers to a great extent. While traditional education has been restricted within classrooms, smart devices can expand educational opportunities to a diverse environment. It creates students as autonomous and lifelong learners. Recently, as COVID-19 has resulted in campuses' closure, educators have begun an unprecedented shift towards online learning using digital technologies. The needy students can also get internet access from borrowed devices. As such, teachers and students can adapt themselves to online learning amidst class suspension. It has become a trend for borderless education and globalization. Cloud is an excellent tool for collaboration and the creation of a virtual classroom environment. Through the video camera, students can observe and listen to everyone. It is a great way to encourage peer groups and allow students to work independently.

Thus, the result of research question 1 clearly reveals that time duration has a significant effect on device type. Gender has no significant effect on device type. Comparing two models, the interaction between time duration and gender is not significant. Hence, there is no significant effect of gender on the perception of using device type controlling for the duration. The result of research question 2 illustrates that time duration has a significant effect on device connectivity. Gender has no significant effect on device connectivity. Comparing two models, the interaction between time duration and gender is significant. Hence, there is a significant effect of gender on perception of device connectivity controlling for the duration. The result of research question 3 depicts that the self-efficacy of the student's participation has a positive impact on online learning.

In our future works, we will continue to assist educators to implement cloud services with the integration of mobile technologies in their institutions for better adoption of the learning environment through efforts and involvements and to predict the academic performance of the students in higher education institutions by implementing machine learning algorithms in the cloud platform.

\section{$9 \quad$ References}

[1] Alex Wilson and Chris Wilson, Gabi Witthaus. (2020). Using a Community of Practice in Higher Education: Understanding the Demographics of Participation and Impact on Teaching. International Journal of Teaching and Learning in Higher Education, 32(1): 39-48

[2] Anna Qian Sun, Xiufang Chen. (2016). Online Education and Its Effective Practice: A Research Review. Journal of Information Technology Education: Research, 15: 157-190. https://doi.org/10.28945/3502 
[3] Christopher B. Davison, Ryan Sims, Brady Sheridan, Silvia Sharna, Justin Bates. (2020). Factors for cloud computing technology adoption: An exploration of scaling strategies. Journal of Technology Research, 9: 1-11

[4] Delna Sebastian, Saravanan KN. (2018). Prediction of Students' Performance in University Level using KNN Classification Algorithm. International Journal for Research in Technological Studies, 5(6): 43-46

[5] Dragan Cvetkovic, Marko Mijatovic, MarijanMijatovic, Branko Medic. Web Service Model for Distance Learning Using Cloud Computing Technologies. MIPRO, Proceedings of the International Convention May 22- 26 2017, Opatija, Croatia. pp. 865-869. https://doi.org/10.23919/mipro.2017.7973543

[6] Eden C. Callo, Alberto D. Yazon. (2020). Exploring the Factors Influencing the Readiness of Faculty and Students on Online Teaching and Learning as an Alternative Delivery Mode for the New Normal. Universal Journal of Educational Research, 8(8): 3509-3518. https://doi.org/10.13189/ujer.2020.080826

[7] Florence Martin, Drew Polly, Shanna Coles and Chuang Wang. (2020). Examining Higher Education Faculty Use of Current Digital Technologies: Importance, Competence, and Motivation. International Journal of Teaching and Learning in Higher Education, 32(1): 73-86

[8] Jyoti Prakash Mishra, Snigdha Rani Panda, BibudhenduPati, Sambit Kumar Mishra. (2019). A Novel Observation on Cloud Computing in Education. International Journal of Recent Technology and Engineering (IJRTE), 8(3): 5262-5274. https://doi.org/10.35940/ ijrte.c5910.098319

[9] Karen Sutherland, Uwe Terton, Cindy Davis, Christina Driver, and Irene Visser. (2020). Academic Perspectives and Approaches to Social Media Use in Higher Education: A Pilot Study. International Journal of Teaching and Learning in Higher Education, 32(1): 1-12

[10] Krishna.M, Bandlamudi S B P Rani, G KalyanChakravarthi, B Madhavrao, S M B Chowdary. (2020). Predicting Student Performance using Classification and Regression Trees Algorithm. International Journal of Innovative Technology and Exploring Engineering (IJITEE), 9 (3): 3349-3356. https://doi.org/10.35940/ijitee.c8964.019320

[11] Maria Drolia, Eirini Sifaki, Stamatios Papadakis and Michail Kalogiannakis. (2020). An Overview of Mobile Learning for Refugee Students: Juxtaposing Refugee Needs with Mobile Applications' Characteristics. Challenges, 11(2),31, https://www.mdpi.com/20781547/11/2/31 https://doi.org/10.3390/challe11020031

[12] Michail Kalogiannakis, Stamatios Papadakis. (2017). Pre-service kindergarten teachers acceptance of "ScratchJr" as a tool for learning and teaching computational thinking and Science education. 12th Conference of the European Science Education Research Association (ESERA), Research, practice and collaboration in science education, Dublin, Ireland

[13] Moh. Muzammil, Adrian Sutawijaya, Dr. Meirani Harsasi. (2020). Investigating Student Satisfaction in Online Learning: The Role of Student Interaction and Engagement in Distance Learning University". Turkish Online Journal of Distance Education-TOJDE, IODLSpecial Issue Article 7. https://doi.org/10.17718/tojde.770928

[14] Patrick Otto, Job Dubihlela, Henrie Benedict. (2020). Employee Usage of Mobile Devices Within South African Municipalities, Implications on Policy and Employee Training. International Journal of Interactive Mobile Technologies, 14(20), https://www.onlinejournals.org/index.php/i-jim/article/view/15747/8355. https://doi.org/10.3991/ijim.v14i20. 1574747

[15] RohitMaheshwari, Dr. SurendraYadav, ParthVidyarthi. (2019). Cloud Computing: A Boon for Education System". International Conference on Advancements in Computing \& Management (ICACM-2019)", Jagannath University, Jaipur, India.pp. 803-808. 
[16] Sonny Rosenthal and Zachary Walker. (2020). Experiencing Live Composite Video Lectures: Comparisons with Traditional Lectures and Common Video Lecture Methods. International Journal for the Scholarship of Teaching and Learning, 14(1): 1-10 https://doi. org/10.20429/ijsotl.2020.140108

[17] Stamatios Papadakis. (2018). Evaluating pre-service teachers' acceptance of mobile devices with regards to their age and gender: a case study in Greece". International Journal of Mobile Learning and Organization, 12 (4) https://doi.org/10.1504/ijmlo.2018.095130

[18] Stamatios Papadakis, Julie Vaiopoulou, Michail Kalogiannakis and Dimitrios Stamovlasis. (2020). Developing and Exploring an Evaluation Tool for Educational Apps (ETEA.) Targeting Kindergarten Children. Sustainability, 12(10), 4201, https://www.mdpi.com/20711050/12/10/4201 https://doi.org/10.3390/su12104201

[19] Stamatios Papadakis, Michail Kalogiannakis, Eirini Sifaki, and Nikolas Vidakis. (2018). Evaluating Moodle use via Smart Mobile Phones. A case study in a Greek University”. EAI Endorsed Transactions on Creative Technologies, 5(16) https://doi.org/10.4108/eai. 10-4-2018.156382

[20] Stamatios Papadakis. (2020). Robots and Robotics Kits for Early Childhood and First School Age. International Journal of Interactive Mobile Technologies, 14 (18): 34-56, https://www.online-journals.org/index.php/i-jim/article/view/16631/8125

[21] Vusala Teymurova, Matanat Abdalova, Saida Babayeva, Vafa Huseynova, Elshan Mammadov. (2020). Implementation of Mobile Entrepreneurial Learning in the Context of Flexible Integration of Traditions and Innovations. International Journal of Interactive Mobile Technologies, 14 (21): 118-135. https://doi.org/10.3991/ijim.v14i21.18445

[22] WenYa Lai, XinHai Wang, ShiYong Zheng, JinDe Huang, Muhammad Safdar Sial, Ubaldo Comite. (2020). A Study on the Impact of Anxiety on the Perception of Communication Engineering Teachers about Self-Efficacy. International Journal of Emerging Technologies in Learning, 15(24): 101-113. https://doi.org/10.3991/ijet.v15i24.18211

\section{Authors}

Arul Leena Rose. P. J. received her Ph.D. degree in the Department of Computer Science, from Mother Teresa Women's University, Kodaikanal. She is currently working as an Associate Professor, Department of Computer Science, College of Science and Humanities, SRM Institute of Science and Technology. Her research interests include image processing, artificial neural networks, cloud computing, big data, machine learning.

Ananthi Claral Mary. T completed her post-graduation from D.J. Academy for Managerial Excellence, Coimbatore. She currently works as a Research Scholar in the Department of Computer Science, College of Science and Humanities, SRM Institute of Science and Technology. Her current research interests include cloud computing, online learning, mobile learning, big data, machine learning.

Article submitted 2021-02-19. Resubmitted 2021-03-26. Final acceptance 2021-03-26. Final version published as submitted by the authors. 